\title{
Spectroscopic investigation of cyanovinyl-diethylaniline dyes in solutions
}

\author{
A.V. Deshpande ', A. Beidoun, A. Penzkofer \\ Naturwissenschaftliche Fakultät II-Physik. Universität Regensburg, D-8400 Regensburg. FRG \\ and \\ G. Wagenblast \\ BASF Aktiengesellschaft. D-6700 Ludwigshafen, FRG
}

Received 26 March 1990; in final form 13 July 1990

\begin{abstract}
Dye solutions of 4-dicyanovinyl-N,N-diethylaniline (DCVA) and 4-tricyanovinyl-N,N-diethylaniline (TCVA) are analysed by absorption and fluorescence spectroscopy. At room temperature the fluorescence quantum yields are very small. Temperature dependent fluorescence quantum efficiency measurements of DCVA in methanol indicate an intrinsic barrierless $S_{1}-S_{0}$ relaxation of the dye molecules. The permanent dipole moments of the molecules in the ground state and excited state are estimated from spectral shifts of the absorption and emission spectra.
\end{abstract}

\section{Introduction}

The aniline (styryl) dyes 4-dicyanovinyl-N,N-diethylaniline (DCVA, 4-diethylamino- $\beta$, $\beta$-dicyanostyrene [1], $p$-(N,N-diethylamino $)$ benzylidene malonitrile $[2,3], p$-diethylaminobenzalmalonitrile [4] ) and 4-tricyanovinyl-N,N-diethylaniline (TCVA, 4-diethylamino- $\alpha, \beta, \beta$-tricyanostyrene (1]) are used for coloring synthetic polymer fibers [1]. They are applied as sublimable dyes in heat-transfer recording materials [5,6] and in photoconductive recording materials [7]. They have received some interest as cytotoxic agents against tumors, as $\mathrm{X}$-ray protective agents, and as stabilizers in plastics against ultraviolet radiation [4].

The structural formulae of DCVA and TCVA are shown below in scheme 1 . The dyes belong to a class of organic compounds known as molecular rotors [811] which have great importance as fluorescence probes of the flexibility of surrounding media [2,817]. Some dicyanovinyl-alkylaniline dyes were ap-

1 On leave from Department of Chemical Technology, University of Bombay, Bombay 400 019, India. plied to determine static and dynamic changes of free volumes and torsional rigidities of polymers [9-16]. The fluorescence behaviour of DCVA was used to study the microviscosity in micellar emulsions [2].

DCVA and TCVA are disubstituted benzenes of the type $\mathrm{D}-\mathrm{Ph}-\mathrm{A}$ with an electron donor $\mathrm{D}$ (diethylamino group) and an electron acceptor $A$ (dicyanovinyl or tricyanovinyl group) $[8,17]$. The electronic excitation of these dyes is accompanied by a large increase in the polarity due to changes in the charge distribution (internal charge transfer) [8-20]. The ground-state and excited-state dipole moments, $\mu_{8}$ and $\mu_{e}$, of some dicyanovinyl-alkylaniline dyes were determined in refs. $[8,12,19,20]$ by measurement of spectral absorption and emission shifts in various solvents. For the dye $p-(\mathrm{N}, \mathrm{N}$-dimethylamino $)$ benzylidene malonitrile which is very similar to DCVA values of $\mu_{\mathrm{g}}=8.7 \mathrm{D}$ and $\mu_{\mathrm{e}}=24 \mathrm{D}$ were measured [8]. The spectral absorption and emission shifts with solvent polarity were utilized to monitor the dye location in polymers when they were used as microviscosity probes $[9,10]$.

In a previous paper we determined thermodynamic and spectral properties of DCVA and TCVA 
in the vapor phase [21]. Very low fluorescence quantum yields were found (of the order of $10^{-4}$, see table 1). Here the absorption and emission spectra of DCVA and TCVA solutions are investigated. Fluorescence quantum yields of the order of $10^{-3}$ are found at room temperature. An increase of the fluorescence quantum yield with decreasing temperature is observed. The results indicate a barrierless $S_{1}$-state deactivation. The spectral shifts of the $S_{0}-S_{1}$ absorption and emission bands in the vapor phase and in several solvents are analysed, and values of the permanent dipole moments of the dyes in the $S_{0}$ ground state and the $S_{1}$ excited state are estimated.

\section{Experimental}

The dyes DCVA and TCVA were synthesized by BASF. A synthesis procedure is described in ref. [1]. The dyes were purified by recrystallization in methanol. Analytic grade solvents from Merck were used without further purification.

The absorption spectra of the dye solutions are measured at room temperature with a conventional spectrophotometer (Beckman ACTA M IV). The fluorescence studies are performed with a self-assembled spectrofluorimeter depicted in fig. 1 [22]. The fluorescence emission in backward direction is collected and resolved spectrally with a grating spectrometer. A mercury lamp LS1 (Osram type HBO 200 $W / 4$ ) together with an interference filter IF form the excitation source. For fluorescence depolarization studies the dichroitic polarizers POL1 and POL2 are inserted. When the transmission directions of the polarizers are aligned to the magic angle $\theta_{M}=54.7^{\circ}$ the fluorescence signal is independent of the orientation of the absorption and emission dipoles and of the temporal reorientation [22-25]. For low-temperature studies the sample cell is placed into a cryostat. The temperature regulation between $20^{\circ} \mathrm{C}$ and $-140^{\circ} \mathrm{C}$ (lowest applied temperature) is achieved by dosing the supply of liquid nitrogen. The detectors PD1 and PD2 measure the absorption of the excitation light in the sample. By adding a light source LS2 (tungsten lamp) and a collimating lens L5 the spectrofluorimeter may be extended to a spectrophotometer for absorption spectra measurements.

\section{Results}

The dyes DCVA and TCVA are studied in some solvents. Detailed data are collected for the solvents methanol, cyclohexane and benzene.

\subsection{Solubility}

The solubility $C_{\text {sat }}$ of the polar dyes DCVA and TCVA in methanol, cyclohexane and benzene at room temperature is listed in table 1 . The solubility is low in the apolar solvent cyclohexane $\left(\approx 10^{-4} \mathrm{~mol} / \mathrm{dm}^{3}\right)$ and reasonably high in the protic solvent methanol $\left(\approx 10^{-2} \mathrm{~mol} / \mathrm{dm}^{3}\right)$ and in the apolar but highly polarizable aromatic solvent benzene $\left(\approx 5 \times 10^{-2} \mathrm{~mol} /\right.$

Table 1

Solubility data and spectroscopic data of DCVA and TCVA at room temperature. Refractive index data are interpolated from data in ref. [77]. The Hildebrand parameters $\delta$ are taken from ref. [27]

\begin{tabular}{|c|c|c|c|c|c|c|c|c|}
\hline & \multicolumn{4}{|l|}{ DCVA } & \multicolumn{4}{|l|}{ TCVA } \\
\hline & vapor & cyclohexane & benzene & methanol & vapor & cyclohexane & benzene & methano \\
\hline$\delta\left(\mathrm{MPa}^{1 / 2}\right)$ & 0 & 16.8 & 18.8 & 29.6 & 0 & 16.8 & 18.8 & 29.6 \\
\hline$C_{\mathrm{sat}}\left(\mathrm{mol} / \mathrm{dm}^{3}\right)$ & - & $\leqslant 10^{-4}$ & 0.09 & 0.02 & - & $\leqslant 10^{-4}$ & 0.03 & 0.01 \\
\hline$n_{\mathrm{A}}$ & 1 & 1.4378 & 1.5245 & 1.3347 & 1 & 1.4315 & 1.5090 & 1.3308 \\
\hline$n_{F}$ & 1 & 1.4358 & 1.5176 & 1.3323 & 1 & 1.4277 & 1.4990 & 1.3269 \\
\hline$q \times 10^{4}$ & 1.3 & 5.3 & 7.3 & 7.3 & 1.6 & 37 & 18 & 7 \\
\hline$\tau_{\text {rad }}$ (ns) & 7.2 & 3.0 & 2.9 & 3.2 & 8.1 & 5.8 & 6 & 6 \\
\hline$\tau_{\mathrm{F}}(\mathrm{ps})$ & 0.9 & 1.6 & 2.1 & 2.3 & 1.3 & 21 & 10.8 & 4.2 \\
\hline $\int_{\text {abs }} \sigma(i) \mathrm{d} i^{i}\left(10^{-13} \mathrm{~cm}\right)$ & 6 & 6 & 5.6 & 7.2 & 4.8 & 4.8 & 5.9 & 5.4 \\
\hline$\sigma_{\mathrm{em}} \sigma_{\mathrm{em}}(i) \mathrm{d} i\left(10^{-13} \mathrm{~cm}\right)$ & 4.3 & 5 & 4.6 & 5.9 & 3.9 & 3.7 & 4 & 4 \\
\hline
\end{tabular}




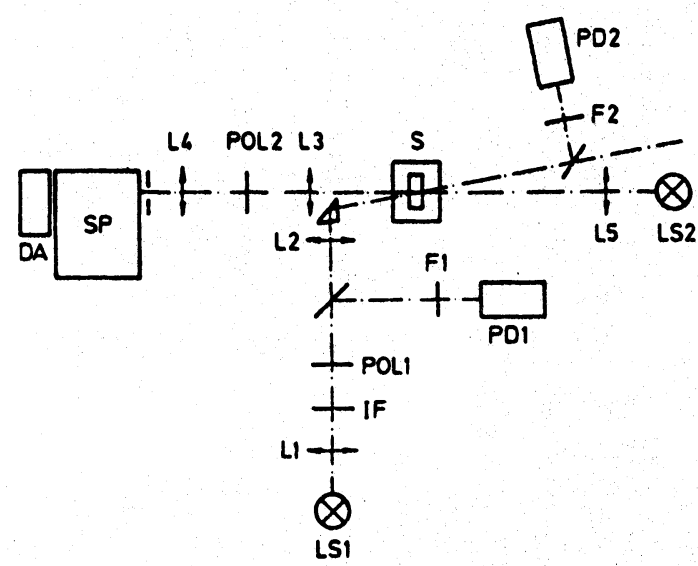

Fig. 1. Experimental setup of spectrofluorimeter. LS1, mercury lamp. L1-L4, lenses. IF, interference filter. POL1, POL2, dichroitic polarizers. F1. F2, filters. PD1, PD2, silicon photodetectors. S. sample. SP, $25 \mathrm{~cm}$ grating spectrometer. DA. diode-array system (Tracor type D.ARRS). LS2, tungsten lamp, and L5, collimating lens for additional transmission measurements.

$\mathrm{dm}^{3}$ ). The solubility is high if the intermolecular attraction forces of two solvent molecules and two solute molecules are less than the intermolecular attraction force between a solvent and solute molecule. The solubility is characterized by the solubility parameter $\delta$ of Hildebrand [26-28] which is the square root of the cohesive pressure. For organic solutes a good solubility is found if the solubility parameter $\delta$ is similar for the solvent and the solute [26-28]. The high solubility in benzene may be due additional to steric fitting and to the high polarizability of benzene (high refractive index). The dyes are practically indissoluble in water (strongly different solubility parameter of $\delta=47.9 \mathrm{MPa}^{1 / 2}$ [27]).

\subsection{Absorption spectra}

The absorption cross-section spectra of DCVA and TCVA in cyclohexane, methanol, and benzene are presented in fig. 2 and fig. 3 , respectively. The vapor absorption spectra [21] are included for comparison. In the apolar solvent cyclohexane the $S_{0}-S_{1}$ absorption band displays a vibronic structure. In the polar hydrogen bonding solvent methanol the spectra are broadened and no vibronic structure is resolved. Benzene behaves similar to methanol, the spectra are broadened and the vibronic structure of

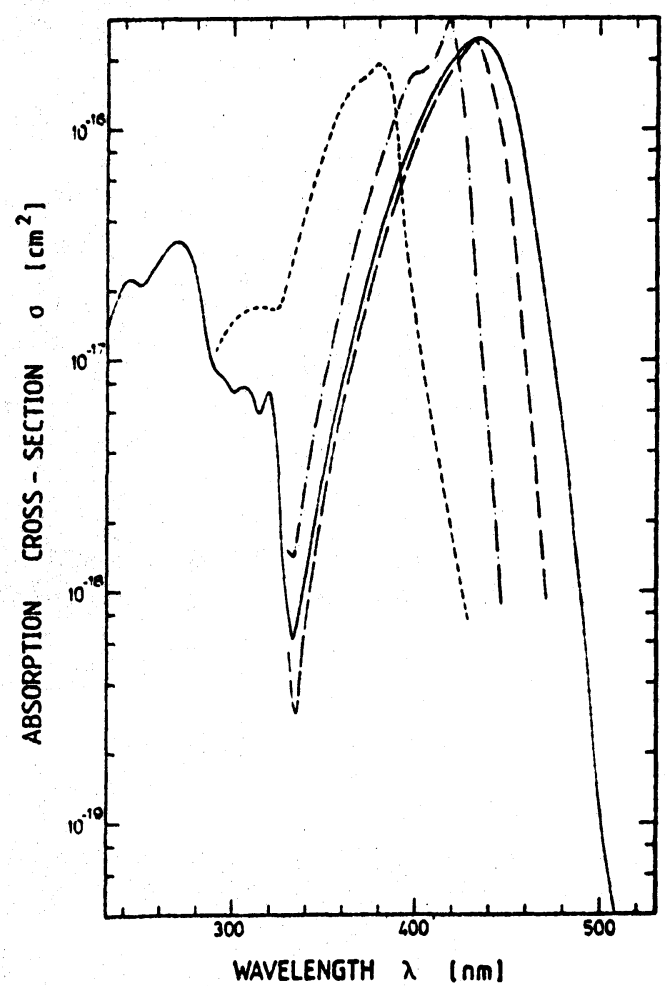

Fig. 2. Absorption cross-section spectra of DCVA vapor (shorndashed curve) and solutions of DCVA in cyclohexane (dashdotted curve), benzene (long-dashed curve), and methanol (solid curve).

the $S_{0}-S_{1}$ absorption band shows up only in a shoulder. The spectral broadening gives some indication of different conformations of the molecules due to solute-solvent interaction [28].

The $S_{0}-S_{1}$ absorption cross-section integrals, $\int_{\mathrm{abs}} \sigma(\tilde{\nu}) \mathrm{d} \tilde{\nu}$. of the dye solutions extending over the $\mathrm{S}_{0}-\mathrm{S}_{1}$ absorption bands are listed in table 1 . The shortwavelength integration limits are set to the first absorption minima above the $S_{0}-S_{1}$ absorption peak.

\subsection{Fluorescence studies}

The fluorescence quantum distributions (quantum spectra of fluorescence) $E(\lambda)[22,29]$ (normalized fluorescence spectra according to $\int_{\mathrm{em}} E\left(\lambda_{i}\right) \mathrm{d} i=$ q) of DCVA and TCVA solutions at room temperature are displayed in fig. $4 \mathrm{a}$ and fig. $4 \mathrm{~b}$, respectively. They arc determined by calibrating the spectral fluo- 


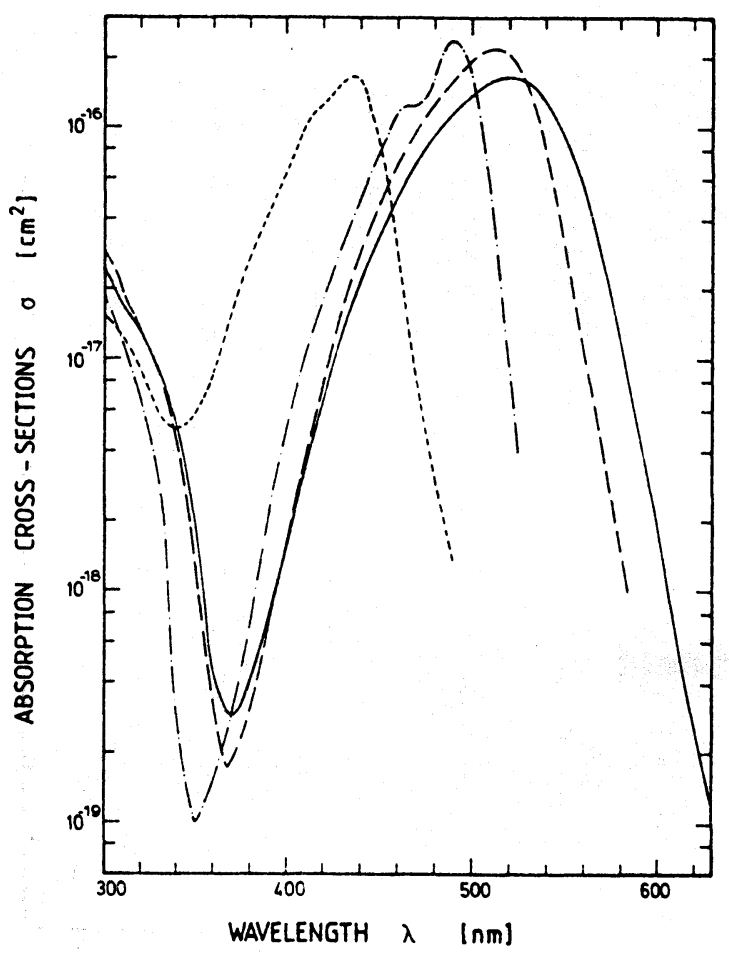

Fig. 3. Absorption cross-section spectra of TCVA vapor (shortdashed curve) and solutions of TCVA in cyclohexane (dashdotted curve), benzene (long-dashed curve), and methanol (solid curve).

rescence signals, $S(i)$, to the total fluorescence sig-

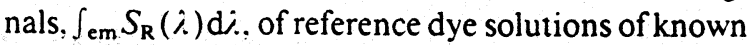
quantum efficiency $q_{\mathrm{R}}[21,22]\left(S(\hat{\lambda})\right.$ and $S_{\mathrm{R}}(\lambda)$ are given in photons per wavelength interval $\left.\left(\mathrm{nm}^{-1}\right)\right)$. The applied reference dye solutions are coumarin $314 \mathrm{~T}$ in ethanol $\left(q_{\mathrm{R}}=0.87 \pm 0.07\right.$ [30], excitation wavelength $\lambda_{\text {exc }}=406 \mathrm{~nm}$ ) for the DCVA solutions, and rhodamine $6 \mathrm{G}$ in ethanol $\left(q_{\mathrm{R}}=0.95 \pm 0.02\right.$ [31], excitation wavelength $\lambda_{\text {exc }}=470 \mathrm{~nm}$ ) for the TCVA solutions. The procedure of calculating $E(\lambda)$ from $S(i)$ and $S_{\mathrm{R}}(i)$ is described in ref. [21] (eq. (8) therein).

The stimulated emission cross-section spectra derived from the fluorescence quantum distributions $E(i)$ (fig. 4 ) and the absorption cross-section spectra $\sigma(\lambda)$ (figs. 2 and 3 ) $[21,32]$ are depicted in fig. 5a (DCVA) and fig. 5b (TCVA). The emission spectra of the dye vapors [21] are included for comparison. The stimulated emission cross-section integrals, $\int_{\mathrm{em}} \sigma_{\mathrm{em}}(\tilde{\nu}) \mathrm{d} \tilde{\nu}$, are given in table 1 . They are slightly

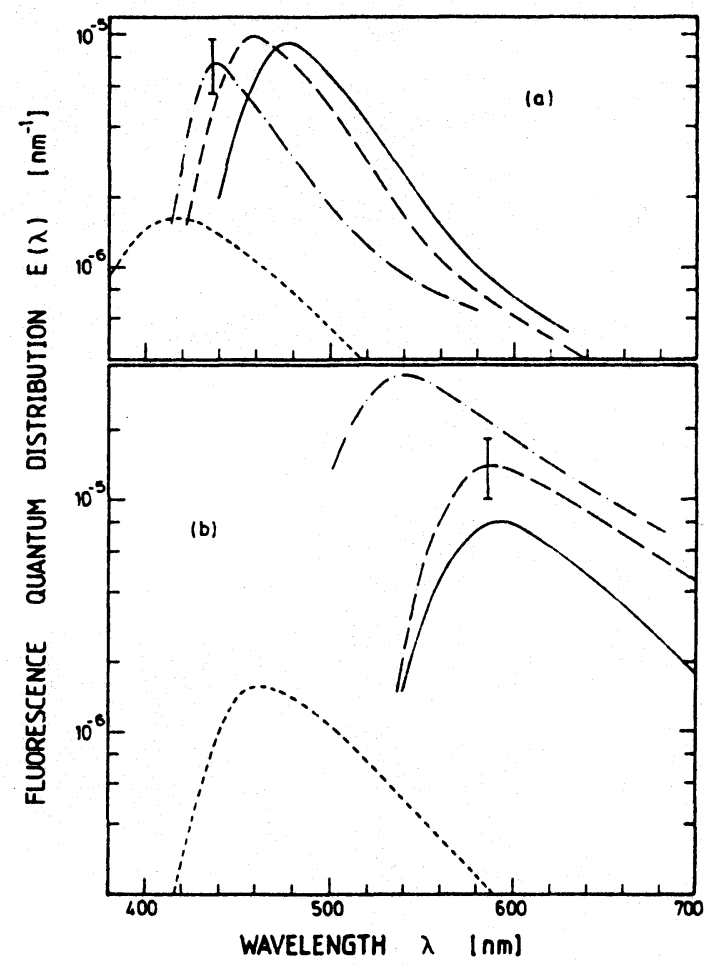

Fig. 4. Fluorescence quantum distributions of DCVA (a) and TCVA (b) in the vapor phase (short-dashed, $\vartheta=150^{\circ} \mathrm{C}$ for DCVA and $\vartheta=210^{\circ} \mathrm{C}$ for TCVA), in cyclohexane (dash-dotted), benzene (long-dashed), and methanol (solid). The solution spectra belong to room temperature.

smaller than the absorption cross-section integrals. It should be noted that the calculated stimulated emission cross-section spectra are only relevant if the emission occurs from the vibrationally or locally relaxed $S_{1}$ state of the same chromophoric system as the absorption spectrum (see fig. 7 below). The absolute values of the stimulated emission cross-section spectra were wrong, if the fluorescence quantum distributions would originate from a modified chromophoric system in the excited state like a twisted internal charge transfer (TICT) state (donor and acceptor group planar in the ground state and perpendicular in excited state ) [33-40].

The vibrationally or locally relaxed $S_{1}$-state lifetimes $\tau_{\text {rad }}$ are calculated by application of the Strickler-Berg formula [41,42] (eq. (10) in ref. [21]) and the obtained values are summarized in table $1 . \tau_{\text {rad }}$ is proportional to $n_{\mathrm{A}} / n_{\mathrm{F}}^{3}[42,43]^{3}$ where $n_{\mathrm{A}}$ is the aver- 


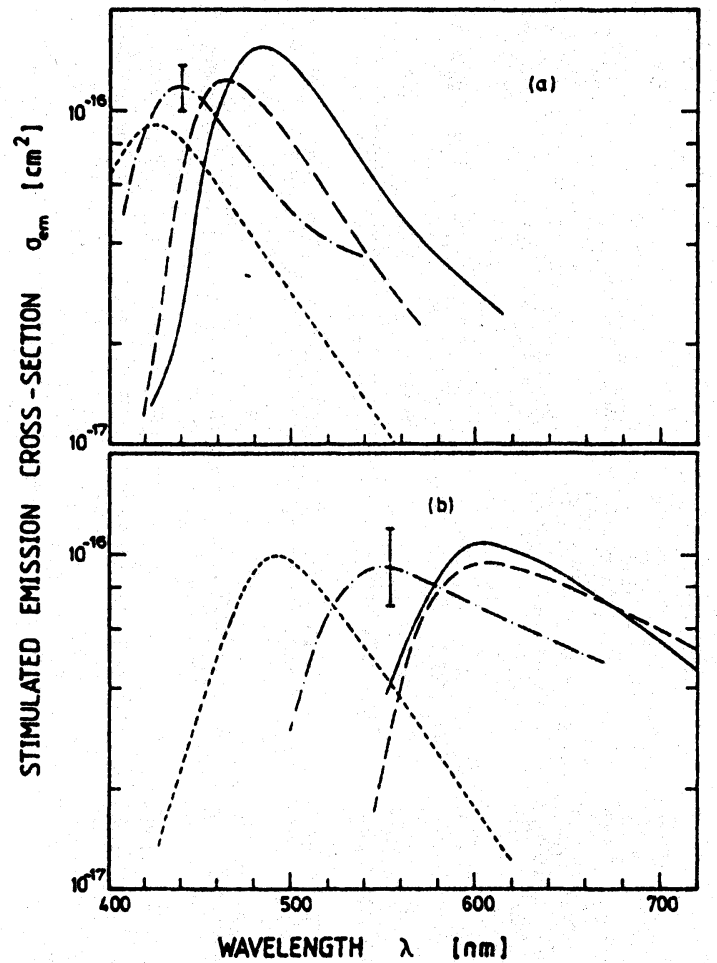

Fig. 5. Stimulated emission cross-section spectra of DCVA (a) and TCVA (b) in vapor phase (short-dashed), in cyclohexane (dash-dotted), benzene (long-dashed), and methanol (solid).

age refraction index in the $S_{0}-S_{1}$ absorption region and $n_{F}$ is the average refractive index in the $S_{1}-S_{0}$ emission region. Therefore the radiative lifetimes are longest in the vapor phase.

The fluorescence quantum efficiencies, $q=$ $\int_{\mathrm{em}} E(\lambda) \mathrm{d} \lambda$, of DCVA and TCVA in methanol, cyclohexane and benzene at room temperature are included in table 1 . The $q$-values are between $5 \times 10^{-4}$ and $4 \times 10^{-3}$. The corresponding fluorescence lifetimes, $\tau_{\mathrm{F}}=\tau_{\mathrm{rad}} q$, are between 2 and 20 ps.

The temperature dependence of the fluorescence quantum efficiency of DCVA in methanol is displayed in fig. $6 \mathrm{a}$. In the liquid state, i.e. for temperatures $\theta>\vartheta_{m}=-97.7^{\circ} \mathrm{C}$, the fluorescence quantum efficiency rises exponentially with the inverse temperature. A similar temperature dependence was observed for TCVA in methanol.

The normalized nonradiative decay rate, $k_{\mathrm{nr}} / k_{\mathrm{rad}}$, of DCVA in methanol is depicted in fig. $6 \mathrm{~b}$. It decreases exponentially with inverse temperature (Ar-

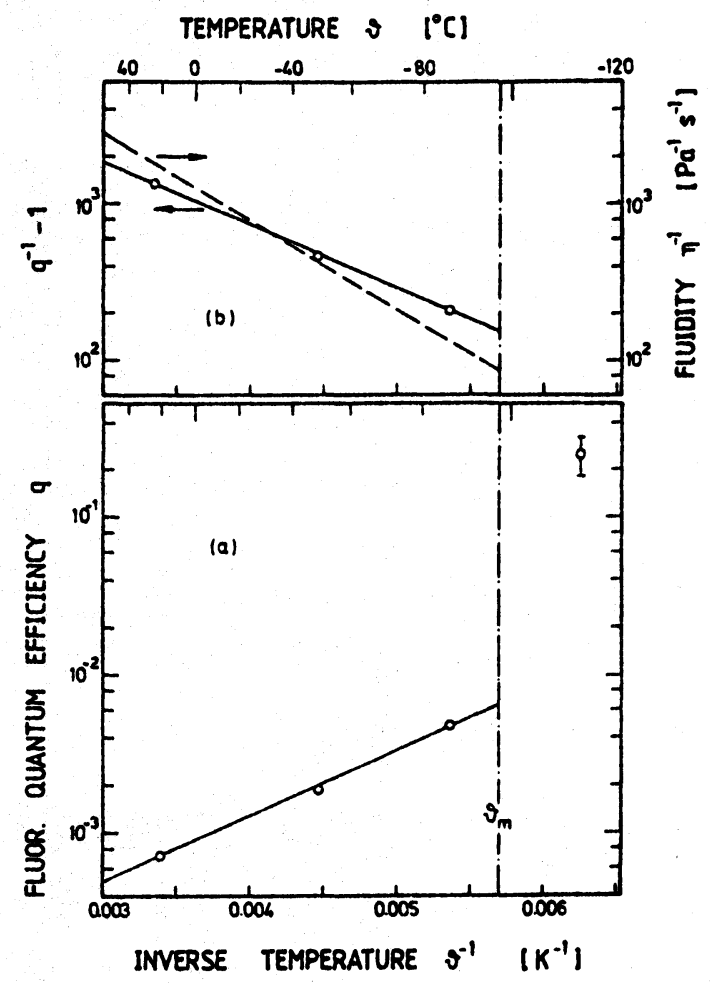

Fig. 6. Fluorescence quantum efficiency (a) and normalized nonradiative decay rate (b) of DCVA in methanol versus temperature (circles and solid lines),$\theta_{\mathrm{m}}=-97.7^{\circ} \mathrm{C}$ is melting temperature of methanol. The fluidity $\eta^{-1}$ is included in (b) (dashed line).

rhenius type behaviour) according to $[44,45]$

$$
\begin{gathered}
\frac{k_{\mathrm{nr}}}{k_{\mathrm{rad}}}=\frac{k_{\mathrm{F}}-k_{\mathrm{rad}}}{k_{\mathrm{rad}}}=\left(\tau_{\mathrm{F}}^{-1}-\tau_{\mathrm{rad}}^{-1}\right) \tau_{\mathrm{rad}} \\
\quad=\frac{1}{q}-1=k_{0} \exp \left(-\frac{E_{\mathrm{A}}+E_{\xi}}{k_{\mathrm{B}} \vartheta}\right)
\end{gathered}
$$

where $k_{0}$ is a pre-exponential factor, $E_{\mathrm{A}}$ is the intrinsic barrier height of the dye molecules which has to be overcome for deactivation, and $E_{\xi}$ is the barrier height caused by the molecular solute-solvent friction $\xi$ [45]. In the case of methanol the molecule solute-solvent friction (microviscosity) $\xi$ is approximately equal to the solvent viscosity $\eta$ and $E_{\xi}$ becomes equal to $E_{\eta}[46]$. The temperature dependence of the fluidity (inverse viscosity) $\eta^{-1}$ follows [45]

$\eta^{-1}=\eta_{0}^{-1} \exp \left(-\frac{E_{\eta}}{k_{\mathrm{B}} \theta}\right)$ 
and is included in fig. $6 \mathrm{~b}$ [47]. A comparison of the slopes of $\ln \left(k_{\mathrm{nr}} / k_{\mathrm{rad}}\right)$ (proportional to $\left.E_{\mathrm{A}}+E_{\eta}\right)$ and $\ln \left(\eta^{-1}\right)$ (proportional to $E_{\eta}$ ) indicates that $E_{\mathrm{A}}$ is approximately zero. This means that the dye molecules relax from the excited $S_{1}$-state by an intrinsic barrierless transition. Only the solute-solvent friction slows down the torsional deactivation [8-17].

In the vapor phase the fluorescence quantum efficiencies of DCVA and TCVA are smallest ( $q$ of the order of $10^{-4}$, see table 1 ) because there is no viscous drag of any solvent $\left(E_{\xi}=0\right)$ and an intrinsic barrier height is absent $\left(E_{\mathrm{A}}=0\right)$.

In the frozen state, i.e. for $\vartheta<\vartheta_{m}=-97.7^{\circ} \mathrm{C}$, the fluorescence quantum efficiency of DCVA in methanol rises to $q=0.25 \pm 0.07$. A similar rise is observed for TCVA in methanol. The solid methanol solutions form strongly scattering microcrystallites. The rotational deactivation is partially hindered.

It should be noted that for DCVA and TCVA in high viscous solutions of glycerol and paraffinic oil at room temperature we measured very low fluorescence quantum yields of $q \leqslant 10^{-3}$. The results indicate a small microviscosity (large free volume at location of dye molecules) despite the high macroscopic viscosity [45]. Small fluorescence quantum yields of similar cyanovinyl-alkylaniline dyes were reported in polymers, and the quantum efficiency measurements were applied to determine the free volume in polymers [8-16]. In DCVA and TCVA films we measured very low fluorescence quantum yields of $q \leqslant 10^{-3}$. In this case energy transfer between nearby molecules may quench the fluorescence signal [4850 ].

The fast non-radiative $S_{1}$-state relaxation is thought to be due to rotational motions of the diethylamino group (rotation a in scheme 1 ) and of the cyanovinyl group (rotations $b$ and $c$ in scheme 1). In ref. [11] strong evidence is given that the rotations $b$ and $c$ of scheme 1 are the dominant decay channels.

The concentration dependence of the fluorescence quantum efficiency was investigated for DCVA in methanol. The concentration was varied between $5 \times 10^{-5} \mathrm{~mol} / \mathrm{dm}^{3}$ and the solubility limit $(\approx 0.02$ $\mathrm{mol} / \mathrm{dm}^{3}$ at room temperature). $q$ was found to be independent of concentration in the investigated temperature region between 22 and $-140^{\circ} \mathrm{C}$.

The degree of "fluorescence polarization, $P=$ $\left(S_{\|}-S_{\perp}\right) /\left(S_{\|}+S_{\perp}\right)$, where $S_{\|}$is the fluorescence component polarized parallel to the polarization of the excitation light and $S_{\perp}$ is polarized perpendicular, was measured for DCVA in methanol at $\vartheta=-85^{\circ} \mathrm{C}$. A value of $P=0.5 \pm 0.05$ was obtained, indicating that the absorption and emission transition dipole moments are parallel to one another and that no molecular reorientation takes place within the short fluorescence lifetime [23-25,51].

\section{Discussion of absorption and emission spectra}

The absorption cross-section spectra (figs. 2 and 3 ) and the stimulated emission cross-section spectra (fig. 5) of the dyes are influenced by the applied solvents. Spectral shifts and spectral broadenings are observed. The spectral broadening indicates the presence of different local dye-solvent conformations with different interaction energies. The spectral shifts of the absorption spectra of the dye solutions compared to the absorption spectra of the dye vapors indicate different solute-solvent interactions in the ground state and the excited state due to molecular dipole and polarizability changes. The difference in the Stokes shift between the absorption and the emission spectra of the solutions and the vapors is due to solvent reorganization after excitation.

In order to understand the observed spectra and to deduce the $S_{0}$ ground-state and $S_{1}$ excited-state permanent dipole moments of DCVA and TCVA from the spectral absorption and emission shifts we review briefly the configurational dynamics of the $S_{0}$ and $S_{1}$ state $[28,52-55]$ in fig. 7 . No intramolecular conformational changes like photoisomerization or TICTstate formation are included in fig. 7.

Fig. 7a describes the situation of dye vapors. The pure electronic frequency difference between the $S_{1}$ and $S_{0}$ state is $\nu_{01}^{v}$. The $S_{0}-S_{1}$ absorption peak is at the frequency position $\nu_{\text {a.p. }}^{v}$. The conformational equilibrium position of the $S_{1}$ state is shifted by the Franck-Condon parameter $\delta_{\mathrm{v}}$ from the ground-state equilibrium position [56]. The excited molecules in the $S_{1}$ state relax to the $S_{1}$-state equilibrium position within the vibrational relaxation time $\tau_{v}^{v}$ which is $<1$ ps [57]. For times $t>\tau_{v}^{v}$ the fluorescence is emitted from the relaxed $S_{1}$ state and the $S_{1}-S_{0}$ emission peak is at $\nu_{\text {e.p }}^{\mathrm{v}}$. This condition is fulfilled in our case since 


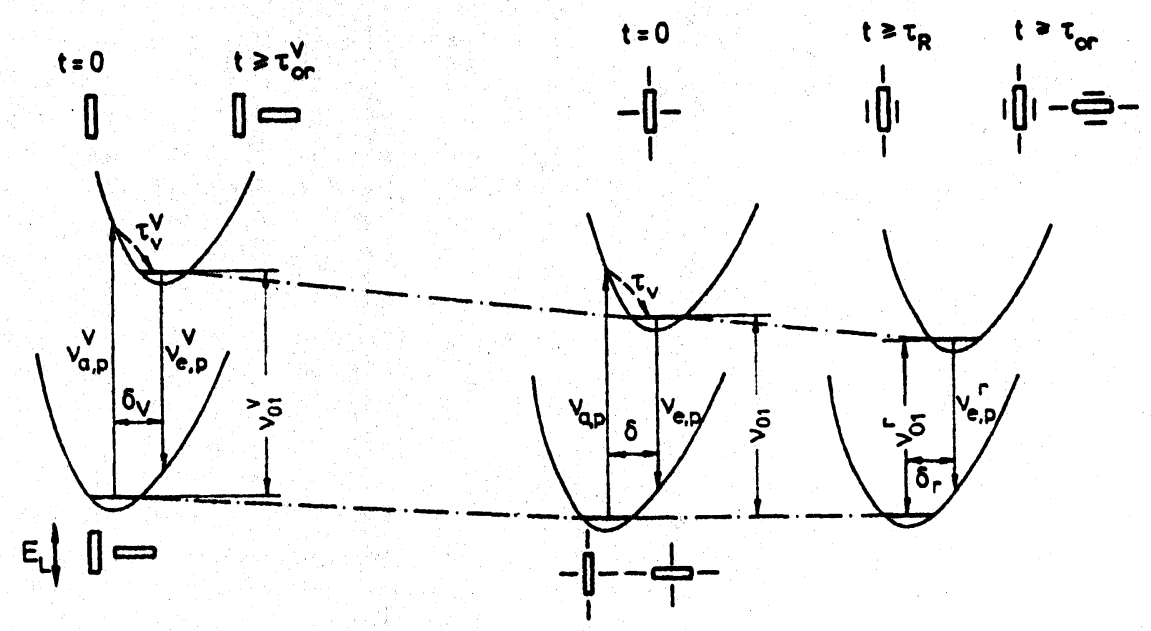

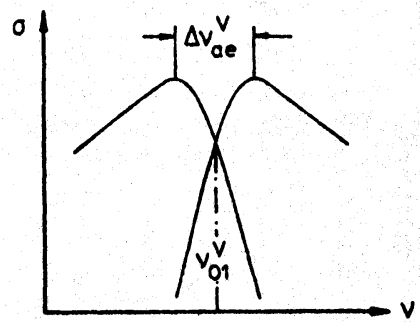

(a)

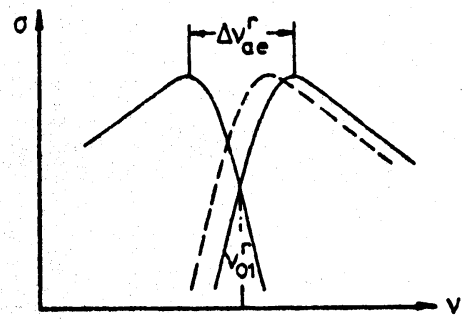

(b)

Fig. 7. Schematic of spectral shifts. (a) Situation of dye vapors. (b) Situation of dye solutions. Explanation is given in text.

the fluorescence lifetime $\tau_{\mathrm{F}}^{\mathrm{v}}$ is of the order of $1 \mathrm{ps}$ (see table 1). The frequency difference between the absorption maximum and the emission maximum $\Delta \nu_{\text {ae }}^{\mathrm{v}}=\nu_{\text {a.p }}^{\mathrm{V}}-\nu_{\text {e.p }}^{\mathrm{v}}$ is proportional to the Franck-Condon parameter $\delta_{\mathrm{v}}$. The photoselectively excited molecules reorient with a reorientation time $\tau_{\text {or }}^{v}[45,58]$.

The spectral situation of dye solutions is illustrated in fig. $7 \mathrm{~b}$. The solute-solvent interaction shifts the potential energy curves of the $S_{0}$ and $S_{1}$ states. The pure electronic $S_{0}-S_{1}$ frequency gap becomes $\nu_{01}$. The $\mathrm{S}_{0}-\mathrm{S}_{1}$ absorption peak lies at $\nu_{\mathrm{a}, \mathrm{p}}$. The Franck-Condon parameter changes to $\delta$. The vibrational relaxation of the excited molecules occurs with the time constant $\tau_{v}$. Around $t=\tau_{v}$ the frequency of peak fluorescence emission is $\nu_{\text {e.p }}$ (dashed curve in $\sigma(\nu)$ picture of fig. $7 \mathrm{~b}$ ). Differences between $\Delta \nu_{\mathrm{ac}}=\nu_{\mathrm{a}, \mathrm{p}}-\nu_{\text {e.p }}$ and $\Delta \nu_{\mathrm{ac}}^{\mathrm{v}}=\nu_{\mathrm{a}, \mathrm{p}}^{\mathrm{v}}-\nu_{\mathrm{e}, \mathrm{p}}^{\mathrm{v}}$ are mainly due to differences in $\delta$ and $\delta_{\mathrm{v}}$ (see data points of apolar solvents in fig. 10 below). Differences in the shapes of the potential energy curves of the vapors and the solutions would contribute to the difference between $\Delta \nu_{\mathrm{ac}}$ and $\Delta \nu_{\mathrm{ac}}^{\mathbf{v}}$. If the excited-state dipole moment of dye molecules is different from the ground-state dipole moment, the surrounding solvent molecules rearrange within the solvent rotation time $\tau_{R}[28,53,55]$. This solvent reorganization lowers the $S_{1}$-state frequency $\nu_{01}$ to the relaxed value $\nu_{0,}^{r}$ and changes the Franck-Condon parameter to $\delta_{r}$ (see fig. 7).

At room temperature the solvent rotation times are of the order of a few picoseconds (see table 2). If the fluorescence lifetime $\tau_{F}$ is longer than the solvent rotation time $\tau_{R}$, then the fluorescence is emitted from the locally relaxed $S_{1}$-state position and the emission peak lies at $\nu_{e, p}^{\text {r.p }}$ giving an absorption-emission spectral shift of $\Delta \nu_{\text {a.e }}^{\mathrm{r}}=\nu_{\text {a.p }}-\nu_{\text {e.p }}^{\mathrm{r}}$. For DCVA and TCVA in methanol and for DCVA in benzene and toluene it is $\tau_{R}>\tau_{F}$ (see data in tables $1-3$ ). In this case the fluorescence spectrum corresponds to a non-relaxed en- 
Table 2

Physico-chemical data of solvents. Parameters belong to room temperature

\begin{tabular}{|c|c|c|c|c|c|c|c|c|c|}
\hline Solvent & Number & $\begin{array}{l}\eta^{2)} \\
\left(10^{-4} \mathrm{~Pa} \mathrm{~s}\right)\end{array}$ & $\begin{array}{l}\tau_{R} \\
(\mathrm{ps})\end{array}$ & $\epsilon_{r}{ }^{a)}$ & $n_{\mathrm{D}}^{20}=$ & $E_{\mathbf{T}}^{N}$ b) & $\begin{array}{l}\chi_{R}{ }^{c)} \\
(\mathrm{kcal} / \mathrm{mol})\end{array}$ & $f(n)$ & $f\left(\epsilon_{r}, n\right)$ \\
\hline cyclohexane & 1 & 9.77 & $1.3^{\mathrm{e})}$ & 2.02 & 1.4262 & 0.006 & 50.0 & 0.2040 & -0.0026 \\
\hline$n$-pentane & 2 & 2.34 & & 1.84 & 1.3575 & 0.009 & & 0.1799 & -0.0006 \\
\hline$n$-hexane & 3 & 3.26 & & 1.88 & 1.3749 & 0.009 & 50.9 & 0.1862 & -0.0021 \\
\hline toluene & 4 & 5.848 & $6.3^{\prime)}$ & 2.38 & 1.4969 & 0.099 & 47.2 & 0.2263 & 0.0225 \\
\hline benzene & 5 & 6.468 & $3.1^{8)}$ & 2.27 & 1.5011 & 0.111 & 46.9 & 0.2276 & 0.0028 \\
\hline chloroform & 6 & 5.8 & & 4.81 & 1.4459 & 0.259 & 44.2 & 0.2105 & 0.2929 \\
\hline acetone & 7 & 3.27 & $0.7^{h)}$ & 20.56 & 1.3587 & 0.355 & 45.7 & 0.1803 & 0.6470 \\
\hline \multicolumn{10}{|l|}{ N,N-dimethyl- } \\
\hline formamide & 8 & $8.45^{d)}$ & $1.4^{h)}$ & 36.71 & 1.4305 & 0.404 & 43.7 & 0.2055 & 0.6639 \\
\hline acetonitrile & 9 & 3.6 & $1.8^{i)}$ & 35.94 & 1.3441 & 0.460 & 45.7 & 0.1748 & 0.7090 \\
\hline methanol & 10 & 5.97 & $12^{j)}, 6.2^{h)}$ & 32.66 & 1.3284 & 0.762 & 43.1 & 0.1688 & 0.7103 \\
\hline
\end{tabular}

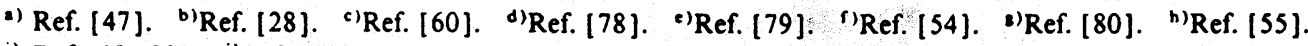

i) Refs. [81,82]. 'jef. [83].

Table 3

Spectroscopic parameters of DCVA and TCVA. Parameters belong to room temperature. $\Delta \tilde{\nu}_{A}$ : spectral halfwidth of absorption crosssection spectra, $\Delta \tilde{\nu}_{\mathrm{F}}$ : spectral halfwidth of fluorescence quantum distribution

\begin{tabular}{|c|c|c|c|c|c|c|c|c|}
\hline Solvent & Number & $\begin{array}{l}\lambda_{A}^{\max } \\
(\mathrm{nm})\end{array}$ & $\begin{array}{l}\lambda_{\mathrm{max}}^{\max } \\
(\mathrm{nm})\end{array}$ & $\begin{array}{l}\Delta \tilde{\nu}_{\hat{A}} \\
\left(\mathrm{~cm}^{-1}\right)\end{array}$ & $\begin{array}{l}\Delta \bar{\nu}_{\mathrm{F}} \\
\left(\mathrm{cm}^{-1}\right)\end{array}$ & $9 \times 10^{4}$ & $\begin{array}{l}\tilde{\nu}_{01}^{\mathrm{r}} \\
\left(\mathrm{cm}^{-1}\right)\end{array}$ & $\begin{array}{l}\Delta \tilde{\nu}_{\mathrm{ac}}^{\mathrm{r}} \\
\left(\mathrm{cm}^{-1}\right)\end{array}$ \\
\hline \multicolumn{9}{|l|}{ DCVA data } \\
\hline vapor & V & 380 & 425 & 2600 & 5600 & 1.3 & 25400 & 2790 \\
\hline cyclohexane & 1 & 418 & 445 & 1900 & 1890 & 5.3 & 23200 & 1450 \\
\hline$n$-pentane & 2 & 415 & 440 & 1900 & 2100 & $\approx 4$ & 23400 & 1370 \\
\hline$n$-hexane & 3 & 415 & 440 & 1850 & 2100 & 7.6 & 23400 & 1340 \\
\hline toluene & 4 & 431 & 473 & 2180 & 2990 & 7.3 & 22190 & 2060 \\
\hline benzene & 5 & 432 & 470 & 2220 & 2820 & 7.3 & 22225 & 1900 \\
\hline chloroform & 6 & 439 & 482 & 2280 & 2830 & 14 & 21750 & 2025 \\
\hline acetone & 7 & 435 & 502 & 2600 & 3300 & 14 & 21450 & 3065 \\
\hline \multicolumn{9}{|l|}{ N,N-dimethyl- } \\
\hline formamide & 8 & 441 & 499 & 2630 & 2760 & 14 & 21160 & 3030 \\
\hline acetonitrile & 9 & 435 & 501 & 2470 & 2740 & 7.4 & 21500 & 3050 \\
\hline methanol & 10 & 435 & 484 & 2670 & 2750 & 7.3 & 21820 & 2330 \\
\hline \multicolumn{9}{|l|}{ TCVA data } \\
\hline vapor & V & 436 & 463 & 2320 & 3620 & 1.6 & 21570 & 2730 \\
\hline cyclohexane & 1 & 490 & 540 & 1780 & 3150 & 37 & 19160 & 2350 \\
\hline benzene & 5 & 514 & 586 & 2390 & 2830 & 18 & 17960 & 2600 \\
\hline methanol & 10 & 520 & 594 & 2870 & 2570 & 7 & 17870 & 2700 \\
\hline
\end{tabular}

vironment of the excited molecules (emission from vibrationally relaxed but locally non-relaxed $S_{1}$-state).

The excited dye molecules themselves reorient with the time constant $\tau_{\text {or }}$ of the order of 100 ps $[45,59]$. This molecular reorientation does not influence the spectral shapes of the absorption and emission spectra.
The solute-solvent interaction of DCVA and TCVA in different solvents may be correlated to the behaviour of standard dyes [28] by comparing the electronic $S_{0}-S_{1}$ transition frequencies. In fig. $8 a$ the experimental pure electronic $S_{0}-S_{1}$ transition frequencies $\tilde{\nu}_{01}^{\mathrm{r}}$ of DCVA (circles) and TCVA (dots) in some solvents are plotted versus Brooker's solvent 

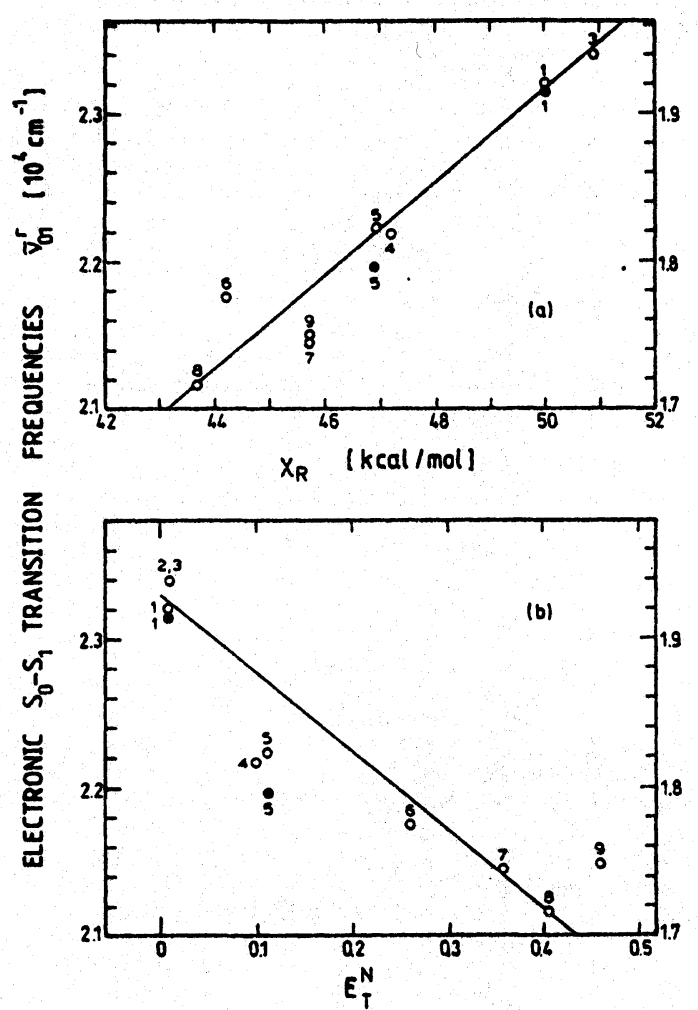

Fig. 8. Plot of pure electronic $S_{0}-S_{1}$ transition frequency $\nu_{01}^{r}$ versus Brooker's solvent property indicator $\chi_{R}$ (a) and versus the normalized solvent polarity parameter $E_{\mathbf{N}}^{N}(b)$. The solvent indication numbers are given in table 2. Circles belong to DCVA and left scale; dots belong to TCVA and right scale.

property indicator $\chi_{R}$ which is defined as the $S_{0}-S_{1}$ transition energy of merocyanine VII in $\mathrm{kcal} / \mathrm{mol}$ [60]. The $\chi_{R}$ parameters of the applied solvents are taken from ref. [60] and collected in table 2 . The $\mathrm{S}_{0}$ $S_{1}$ transition frequencies of DCVA and TCVA are calculated by $\tilde{\nu}_{01}^{r}=\left[\left(\lambda_{A}^{\max }\right)^{-1}+\left(\lambda_{\mathrm{F}}^{\max }\right)^{-1}\right] / 2$ where $\lambda_{A}^{\max }$ is the wavelength of maximum $S_{0}-S_{1}$ absorption cross section and $\lambda_{\mathrm{F}}^{\max }$ is the wavelength of maximum stimulated emission cross section. The $\tilde{\nu}_{01}^{r}$ values of the DCVA and TCVA solutions correlate reasonably with the $\chi_{R}$ parameter. The solvent methanol is excluded. For this solvent the relaxed $S_{1}$-state position $\tilde{\nu}_{01}^{r}$ is not reached within the $S_{1}$-state lifetime since the fluorescence lifetime $\tau_{F}$ is shorter than the solvent reorientation time $\tau_{R}$ (see tables 1 and 2 ). In fig. 8b the transition frequencies $\tilde{\nu}_{0}^{\text {r }}$ of DCVA (circles) and
TCVA (dots) are displayed versus the normalized solvent polarity parameter $E_{\mathrm{T}}^{\mathrm{N}}[28,61]$. The $E_{\mathrm{T}}^{\mathrm{N}} \mathrm{pa}$ rameter is define by $E_{\mathrm{T}}^{\mathbf{N}}=\left[E_{T}(30)-30.7 \mathrm{kcal}\right.$ $\left.\mathrm{mol}^{-1}\right] / 32.4 \mathrm{kcal} \mathrm{mol}^{-1}$ where $E_{\mathrm{T}}(30)$ is the electronic $S_{0}-S_{1}$ transition energy of pyridinium-Nphenoxide betaine $[28,62,63]$. Again a reasonable correlation of $\bar{\nu}_{01}^{r}$ with $E_{\mathbf{N}}^{N}$ is obtained. The solvent methanol is excluded because the fluorescence emission in this solvent does not occur from the locally relaxed $S_{1}$ state. It would strongly deviate from the straight time $\left(E_{\mathrm{T}}^{\mathrm{N}}=0.762, \tilde{\nu}_{01}=21820 \mathrm{~cm}^{-1}\right.$ for DCVA, and $\tilde{\nu}_{01}=17870 \mathrm{~cm}^{-1}$ for TCVA). In figs. 8a and $8 \mathrm{~b}$ the data points of toluene (4) and benzene (5) are included, but they also do not belong to locally relaxed emission from the $S_{1}$ state.

\section{Determination of ground state and excited state dipole moments}

In the following the spectral shifts of the absorption and emission spectra are analysed to determine the permanent dipole moments in the $\mathrm{S}_{0}$ ground state and $S_{1}$ excited state. The solvents methanol, benzene, and toluene are excluded from the analysis because the fluorescence spectra from the locally relaxed $S_{1}$ states are unknown. Complete data for DCVA and fragmentary data for TCVA are presented.

\subsection{Determination of $\mu_{e}-\mu_{g}$ by fluorescence Stokes shift analysis}

The frequency difference $\Delta \tilde{\nu}_{\mathrm{ac}}^{\mathrm{r}}$ between the absorption and fluorescence peaks is given by [64]

$$
\begin{aligned}
& \Delta \tilde{\nu}_{\mathrm{ae}}^{\mathrm{r}}=\frac{\Delta \nu_{\mathrm{ac}}^{\mathrm{r}}}{c_{0}}=\Delta \tilde{\nu}_{\mathrm{ac}}^{\mathrm{v}} \\
& +\frac{1}{2 \pi \epsilon_{0} h a^{3} c_{0}}\left(\frac{\epsilon_{\mathrm{r}}-1}{\epsilon_{\mathrm{r}}+2}-\frac{n^{2}-1}{n^{2}+2}\right)\left(\mu_{\mathrm{e}}-\mu_{\mathrm{B}}\right)^{2} \\
& +\Delta \tilde{\nu}_{\mathrm{ae}}\left(\delta_{\mathrm{v}}, \delta_{\mathrm{r}}\right),
\end{aligned}
$$

where $\epsilon_{0}$ is the permittivity of vacuum, $h$ is the Planck constant, $a$ is the dye cavity radius, $\epsilon_{\mathrm{r}}$ is the dielectric constant, and $n$ the refractive index $\left(n=n\left(\nu_{01}^{\prime}\right)\right)$. Spectral shifts due to changes of the Franck-Condon parameter are taken into account by the term $\Delta \tilde{\nu}_{\mathrm{ac}}\left(\delta_{\mathrm{v}}, \delta_{\mathrm{r}}\right)\left(\approx \Delta \tilde{\nu}_{\mathrm{ac}}\left(\delta_{\mathrm{v}}, \delta\right)\right)$. Similar formulae are given in refs. $[28,33,34,52,65,66]$. The spectral ab- 
sorption-emission difference depends strongly on the dye cavity radius $a$. This parameter is determined from the molecular structures of DCVA and TCVA which are displayed in fig. 9. The atomic distances are taken from refs. [67,68]. A value of $a=0.6 \mathrm{~nm}$ is estimated for both molecules (see also ref. [8]).

In fig. 10 the $\Delta \tilde{\nu}_{\text {ae }}^{\mathrm{r}}$ data of DCVA are plotted versus the dielectric function

$f\left(\epsilon_{\mathrm{r}}, n\right)=\left(\epsilon_{\mathrm{r}}-1\right)\left(\epsilon_{\mathrm{r}}+2\right)^{-1}-\left(n^{2}-1\right)\left(n^{2}+2\right)^{-1}$.

The $\Delta \tilde{\nu}_{\mathrm{ae}}^{\mathrm{v}}$ value is included. $n$ is approximated by $n_{\mathrm{D}}^{20}=n\left(\lambda=589.3 \mathrm{~nm}, \vartheta=20^{\circ} \mathrm{C}\right)$. The $\epsilon_{\mathrm{r}}$ and $n_{\mathrm{D}}^{20} \mathrm{val}-$ ues are listed in table 2 [28]. The deviation between $\Delta \tilde{\nu}_{\mathrm{ae}}^{\mathrm{r}}$ of the apolar solvents $\left(f\left(\epsilon_{\mathrm{r}}, n\right) \approx 0\right)$ and $\Delta \tilde{\nu}_{\mathrm{ae}}^{\mathrm{v}}$ are thought to be due to changes in the Franck-Condon parameter (term $\left.\Delta \tilde{\nu}_{\mathrm{ae}}\left(\delta_{\mathrm{v}}, \delta_{\mathrm{r}}\right)\right)$. From the solution data in fig. 10 a value of $\left|\mu_{\mathrm{e}}-\mu_{\mathrm{g}}\right|=$ $(2.4 \pm 0.2) \times 10^{-29} \mathrm{C} \mathrm{m}=7.3 \pm 0.6 \mathrm{D}$ is obtained for DCVA $\left(1 \mathrm{D}=3.3 \times 10^{-30} \mathrm{C} \mathrm{m}\right)$. A similar value is expected for TCVA.

\subsection{Determination of $\mu_{g}$ from spectral shifts of absorption spectra}

The solvent induced spectral shift, $\Delta \tilde{\nu}_{01}=\tilde{\nu}_{01}^{v}-$ $\tilde{\nu}_{01}^{\mathrm{r}}$, of the pure electronic $S_{0}-S_{1}$ transition frequency is theoretically given by [64]

$$
\begin{aligned}
& \Delta \tilde{\nu}_{01}^{\mathrm{r}}=J \frac{n^{2}-1}{2 n^{2}+1}+\frac{\mu_{\mathrm{c}}^{2}-\mu_{\mathrm{g}}^{2}}{4 \pi \epsilon_{0} h c_{0} a^{3}} \frac{n^{2}-1}{2 n^{2}+1} \\
& +\frac{\mu_{\mathrm{g}}\left(\mu_{\mathrm{e}}-\mu_{\mathrm{g}}\right)}{2 \pi \epsilon_{0} h c_{0} a^{3}}\left(\frac{\epsilon_{\mathrm{r}}-1}{\epsilon_{\mathrm{r}}+2}-\frac{n^{2}-1}{n^{2}+2}\right) \\
& +K \frac{\left(\epsilon_{\mathrm{r}}-n^{2}\right)\left(2 \epsilon_{\mathrm{r}}+n^{2}\right)}{\epsilon_{\mathrm{r}}\left(n^{2}+2\right)^{2}} .
\end{aligned}
$$

The first term is due to dispersion force interaction (London forces) and is present in all solutions. $J$ is a dye molecule dependent constant. The second term describes the interaction of the solute dipole with the induced dipole moment of the solvent (solute Stark effect, depends on solvent polarizability). This term is most important for polar molecules in apolar solvents. The third term describes the solute-dipole-sol-
DCVA
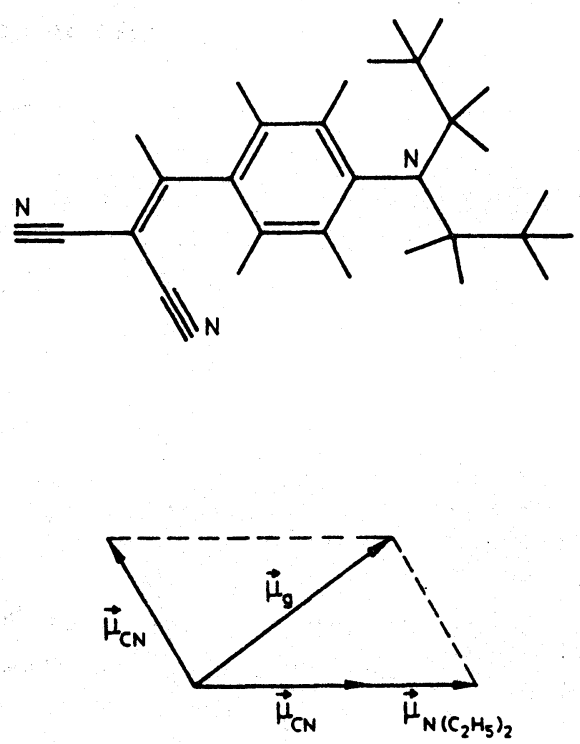

TCVA
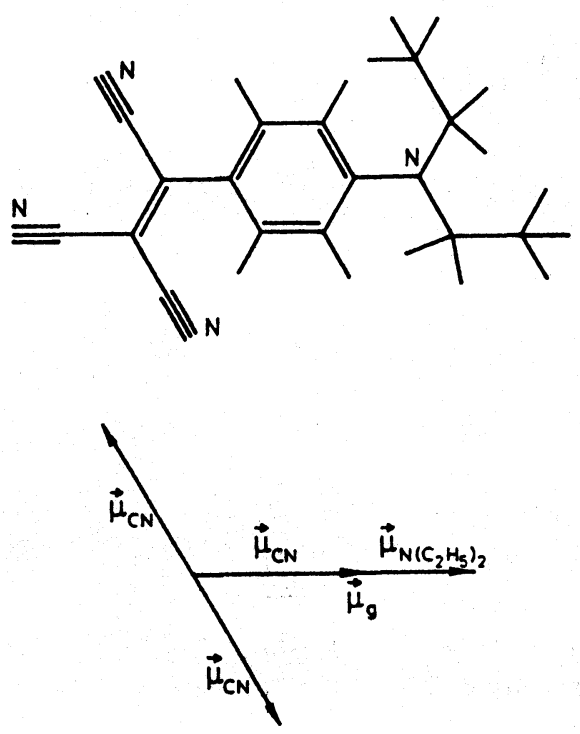

Fig. 9. Molecular structures and vector addition of group dipoles of DCVA (left part) and TCVA (right part). The bonding lengths are [67.68] C-C: $0.1541 \mathrm{~nm}, \mathrm{C}=\mathrm{C}: 0.1337 \mathrm{~nm}, \mathrm{C}-\mathrm{N}: 0.1472 \mathrm{~nm}, \mathrm{C}=\mathrm{N}: 0.1158 \mathrm{~nm}, \mathrm{C}-\mathrm{H}: 0.109 \mathrm{~nm}, \mathrm{C}-\mathrm{C}$ in benzene: $0.1395 \mathrm{~nm}$. The group dipoles are [69]: $\mu_{\mathrm{CN}}=-3.8 \mathrm{D}$, and $\mu_{\left.\mathrm{N}_{(} \mathrm{C}_{2} \mathrm{H}_{3}\right)_{2}} \approx \mu_{\mathrm{N}_{(}\left(\mathrm{CH}_{3}\right)_{2}}=2: 6 \mathrm{D}$. 


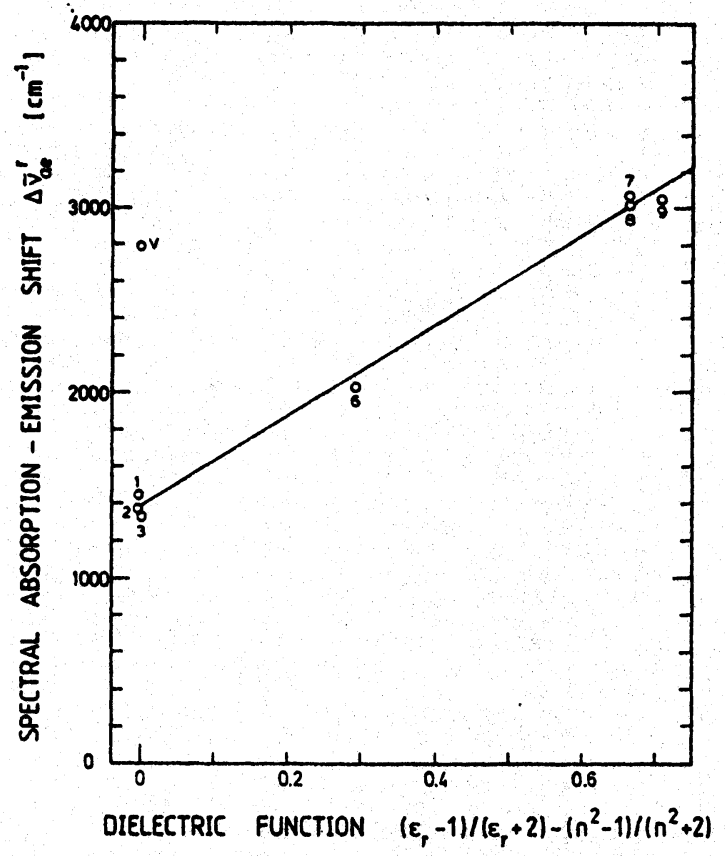

Fig. 10. Spectral absorption-emission shift $\Delta \tilde{\nu}_{\text {ae }}^{\prime}$ of DCVA versus dielectric function $f\left(\epsilon_{r}, n\right)=\left(\epsilon_{r}-1\right) /\left(\epsilon_{r}+2\right)-\left(n^{2}-1\right) /\left(n^{2}+2\right)$. $n$ is approximated by $n_{D}^{20}$. The solvent identification numbers are given in table 2.

vent-dipole interaction. It is important for polar molecules in polar solvents. The last term gives the interaction of the solvent dipoles with the induced solute dipoles (solvent Stark effect). It is important for apolar molecules in polar solvents. $K$ is a constant that depends on solute and solvent parameters.

The molecules DCVA and TCVA are asymmetric and have dipolar groups. For these polar dyes in apolar solvents eq. (4) reduces to

$$
\begin{aligned}
& \Delta \tilde{\nu}_{01}^{\mathrm{r}}=\left(J+\frac{\mu_{\mathrm{e}}^{2}-\mu_{\mathrm{g}}^{2}}{4 \pi \epsilon_{0} h c_{0} a^{3}}\right) \frac{n^{2}-1}{2 n^{2}+1} \\
& =A \frac{n^{2}-1}{2 n^{2}+1}=A f(n)
\end{aligned}
$$

where $A$ abbreviates the term in the brackets.

The spectral shifts $\Delta \tilde{\nu}_{01}^{r}$ versus the refractive index function $f(n)=\left(n^{2}-1\right) /\left(2 n^{2}+1\right)$ are plotted in fig. 11 for the apolar solvents. The fit to eq. (5) gives $A=(1.1 \pm 0.04) \times 10^{4} \mathrm{~cm}^{-1}$ for DCVA and $A \approx$ $1.16 \times 10^{4} \mathrm{~cm}^{-1}$ for TCVA.

In polar solvents only that last term of eq. (4) (sol-

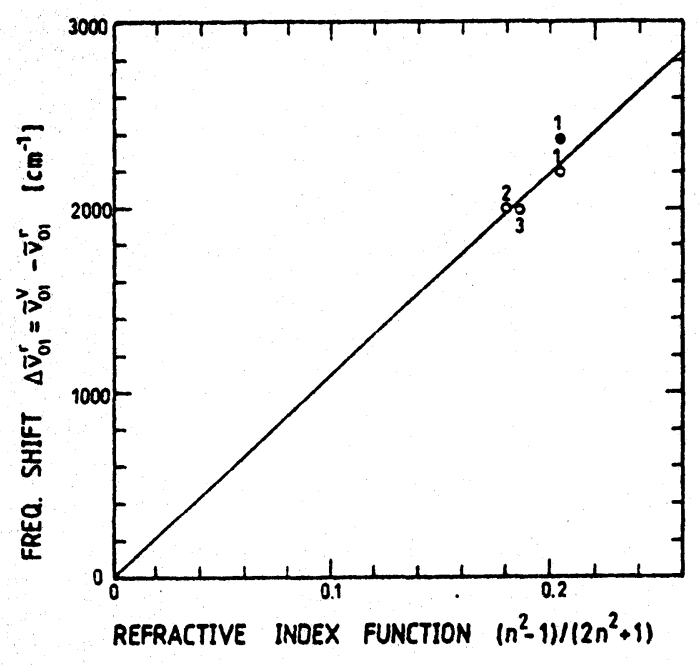

Fig. 11. Spectral shift of zero-vibration $\mathrm{S}_{0}-\mathrm{S}_{1}$ transition frequencies, $\Delta \tilde{\nu}_{01}^{r}=\tilde{\nu}_{01}^{v}-\tilde{\nu}_{01}^{r}$, versus refractive index function $f(n)=\left(n^{2}-1\right) /\left(2 n^{2}+1\right)$ in apolar solvents. Circles belong to DCVA, dot belongs to TCV.A. Line is fitted through DCVA data. The solvent identification numbers are given in table 2 .

vent Stark effect) may be neglected. Solving the reduced eq. (4) to $\mu_{\mathrm{g}}$ gives

$\mu_{\mathrm{g}}=\frac{\Delta \tilde{\nu}_{01}^{\mathrm{r}}-A f(n)}{f\left(\epsilon_{\mathrm{r}}, n\right)\left(\mu_{\mathrm{e}}-\mu_{\mathrm{g}}\right)} 2 \pi \epsilon_{0} h c_{0} a^{3}$.

The calculated $\mu_{\mathrm{B}}$ values of DCVA for the polar solvents chloroform (6), acetone (7), N,N-dimethylformamide (8), and acetonitrile (9) are displayed in fig. 12 versus $\tilde{\nu}_{01}^{r}$. Averaging gives $\mu_{\mathrm{g}}=(2.4 \pm$ $0.5) \times 10^{-29} \mathrm{C} \mathrm{m}$. From $\mu_{8}=(2.4 \pm 0.5) \times 10^{-29} \mathrm{C} \mathrm{m}$ and $\mu_{\mathrm{c}}-\mu_{\mathrm{g}}=(2.4 \pm 0.2) \times 10^{-29} \mathrm{C} \mathrm{m}$ the permanent excited dipole moment is calculated to be $\mu_{\mathrm{e}}=(4.8 \pm 0.7) \times 10^{-29} \mathrm{C} \mathrm{m}$. Insertion of $\mu_{\mathrm{e}}$ and $\mu_{\mathrm{s}}$ into $A$ gives $J=7400 \pm 1400 \mathrm{~cm}^{-1}$. The determined permanent dipole moments of DCVA are collected in table 4.

Theoretical values of the permanent ground-state dipole moments $\mu_{\mathrm{g}}$ may be obtained by vector addition of the dipole moments of the polar groups of the dye molecules [69]. This vector addition is performed in fig. 9. The resulting values are $\mu_{g}(D C V A) \approx 5.6 D$ and $\mu_{g}($ TCVA $) \approx 6.4 \mathrm{D}$. The vector addition value of DCVA is approximately $75 \%$ of the average value obtained from the spectroscopic analysis. One reason of the deviation may be the unaccurately known value of the dye cage radius $a$. In 


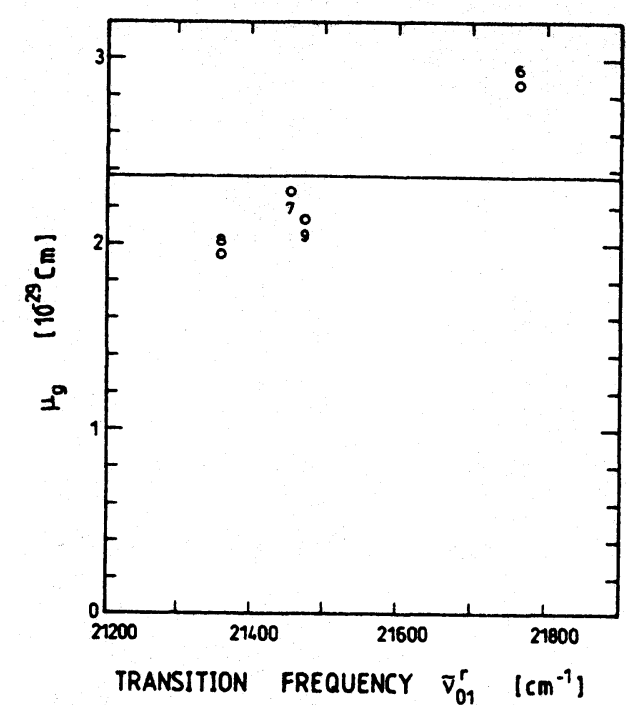

Fig. 12. Permanent ground-state dipole moments $\mu_{2}$ versus zerovibration $S_{0}-S_{1}$ transition frequencies, $\Delta \tilde{\nu}_{01}$, for DCVA in polar solvents. The solvent identification numbers are given in table 2 .

\section{Table 4}

Permanent dipole moments of DCVA. The cage radius is set to $a=d_{\max } / 2=0.6 \mathrm{~nm}$

\begin{tabular}{lll}
\hline Parameter & \multicolumn{1}{l}{ Value } \\
\cline { 2 - 3 } & $\left(10^{-29} \mathrm{C} \mathrm{m}\right)$ & (D) \\
\hline$\mu_{8}$ & $2.4 \pm 0.5$ & $7.3 \pm 1.5$ \\
$\mu_{\mathrm{e}}$ & $4.8 \pm 0.7$ & $14.6 \pm 2.1$ \\
$\mu_{\mathrm{e}}-\mu_{\mathrm{s}}$ & $2.4 \pm 0.2$ & $7.3 \pm 0.6$ \\
\hline
\end{tabular}

the calculations $a$ was set equal to half the outmost diameter $d_{\max }$ of the molecule. A value of $a=0.46 d_{\max }$ gives an agreement between the spectroscopic and the vector addition results.

\subsection{Discussion of results of dipole moment measurements}

The increased excited-state dipole moments are thought to be due to some charge transfer in the excited state $[11,17,18,28]$ according to scheme 1, where $\mathrm{R}=\mathrm{H}$ for DCVA and $\mathrm{R}=\mathrm{CN}$ for TCVA.

A complete electron transfer - as indicated by the formula at the right-hand side of scheme' 1 - would result in a change of the dipole moments of $\mu_{\mathrm{c}}-$ $\mu_{\mathrm{g}} \approx 1.1 \times 10^{-28} \mathrm{C} \mathrm{m}=34 \mathrm{D}$ by excitation (charge separation $\approx 0.7 \mathrm{~nm}$ ). The experimental increase is approximately a factor of five smaller, i.e. only a partial internal charge transfer occurs.

The observed spectral shifts at room temperature are well interpreted by fluorescence emission from a locally relaxed $S_{1}$ state with a partial internal charge transfer (for DCVA and TCVA in methanol and for DCVA in benzene and toluene emission occurs from vibrationally relaxed but environmently non-relaxed $S_{1}$ state because of slow environment rearrangement an fast nonradiative relaxation). There are no indications of the formation of a TICT state like the occurrence of a far-red shifted second fluorescence maximum in polar solvents due to a complete charge transfer in the excited-state and the elevation of the TICT ground state by its diradical nature [33$40,55,70,71]$.

It should be emphasized that the described procedure of determining the permanent ground-state and excited-state dipole moments would not be applicable if TICT states were formed because then the chromophoric system would be modified (twisted configuration corresponds to zwitterionic excited state and to energetically elevated biradical ground state) $[35-38,71]$.

\section{Conclusions}

A linear absorption and emission spectroscopic analysis of the dyes DCVA and TCVA was carried out. The small fluorescence quantum efficiency of the dyes hinders their application in dye lasers, but the

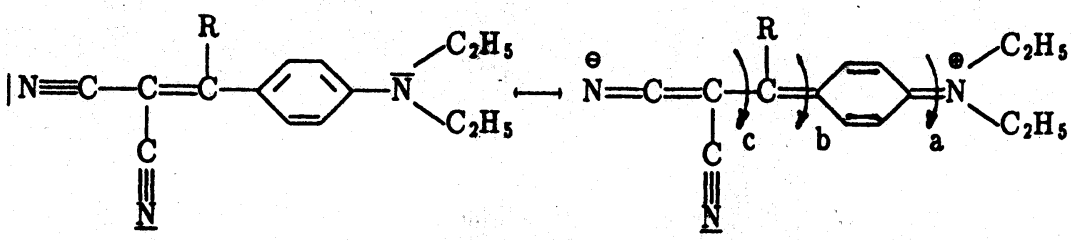

Scheme 1. 
dyes should be applicable as gain media in dye laser generators (amplified spontaneous emission) pumped by intense picosecond [ 72-74] or femtosecond [75] laser pulses. The fast nonradiative $S_{1}-S_{0}$ relaxation makes the dyes good candidates for fast saturable absorbers [76]. If the excited-state absorption of the dye solutions is small they may be applied as fast saturable absorbers in the spectral region between $380 \mathrm{~nm}$ and $580 \mathrm{~nm}$ (DCVA in cyclohexane: $380 \mathrm{~nm}$ to $430 \mathrm{~nm}$; DCVA in methanol: $400 \mathrm{~nm}$ to $470 \mathrm{~nm}$; TCVA in cyclohexane: $450 \mathrm{~nm}$ to $510 \mathrm{~nm}$; TCVA in methanol: $460 \mathrm{~nm}$ to $580 \mathrm{~nm}$ ).

The analysis of the spectral absorption-emission differences $\Delta \tilde{\nu}_{\text {ae }}^{r}$ and of the zero-vibration $S_{0}-S_{1}$ transition frequency shifts $\Delta \tilde{\nu}_{0}^{\text {r }}$ seems to give reasonable data of the molecular ground-state and excited-state dipole moments $\mu_{\mathrm{g}}$ and $\mu_{\mathrm{e}}$.

\section{Acknowledgement}

The authors thank the Deutsche Forschungsgemeinschaft for financial support.

\section{References}

[1] A.T. Peters and M.S. Wild, J. Soc. Dyers Colour 93 (1977) $126,133$.

[2] N.E. Tonks Jr., Dissertation, University of Georgia, Athens, GA, USA (1986) (available: Univ. Microfilms Int., Order No. DA8613520).

[3] S.S. Beavan. J.S. Hargreave and D. Phillips, Advan Photochem. 11 (1979) 207.

[4] S.S.M. Hassan, J.M. Abdella and N.E. Nashed, Mikrochimica Acta II (1984) 27.

[5] N. Taguchi, A. Imai, T. Niwa and Y. Murata, Eur. Pat. Appl. EP 163145 A2 (4 December 1985).

[6] Mitsubishi Chemical Industries Co. Ltd., Jpn. Kokai Tokyo Koho JP89/78895A2 [84/78895] (7 August 1984).

[7] H.E. Wright and M.A. Berwick, Res. Discl. 158 (1977) 62.

[8] R.O. Loutfy and K.Y. Law, J. Phys. Chem. 84 (1980) 2803.

[9] R.O. Loutfy, Pure Appl. Chem. 58 (1986) 1239.

[10] R.O. Loutfy, in: Photophysical and Photochemical Tools in Polymer Science, ed. M.A. Wimnik (Reidel, Dordrecht, 1986) pp. $429 \mathrm{ff}$.

[11] M.S.A. Abdel-Mottaleb, R.O. Loutfy and R. Lapouyade, J. Photochem. Photobiol. A 48 (1989) 87.

[12] R.O. Loutfy and K.Y. Law, Macromolecules 14 (1981) 587.

[13] K.Y. Law, Chem. Phys. Letters 75 (1980) 545.

[14] K.Y. Law. Photochem. Photobiol. 33 (1981) 799.

[15] R.O. Loutfy and B.A. Arnold, J. Phys. Chem. 86 (1982) 4205 .
[16] R.O. Loutfy, Macromolecules 16 (1983) 678.

[17] A. Safarzadeh-Amiri, Can. J. Chem. 62 (1984) 1895.

[18] J. Aihara, K. Araya and Y. Matsunaga, Bull. Chem. Soc. Japan 54 (1981) 615.

[19] R.O. Loutfy, Macromolecules 14 (1981) 270.

[20] R.O. Loutfy, J. Polym. Sci. Polymer Phys. Ed. 20 (1982) 825.

[21] A.V. Deshpande, A. Beidoun, A. Penzkofer and G. Wagenblast, Chem. Phys. 142 (1990) 123.

[22] A Penzkofer and W. Leupacher, J. Luminescence 37 (1987) 61.

[23] E.D. Cehelnik. K.D. Mielenz, and R.A. Velapoldi, J. Res. Nat. Bur. Std. A 79 (1975) 1

[24] A. von Jena and H.E. Lessing, Ber. Bunsenges. Physik. Chem. 83 (1979) 181.

[25] T. Tao, Biopolymers 8 (1969) 609.

[26] J.H. Hildebrand, J.M. Prausnitz and R.L. Scott, Regular and Related Solutions (Van Nostrand-Reinhold, Princeton. 1970).

[27] A.F.M. Barton, Handbook of Solubility Parameters and Other Cohesion Parameters (CRC Press, Boca Raton, 1983).

[28] C. Reichardt, Solvents and Solvent effects in Organic Chemistry (VCH, Weinheim, 1988).

[29] J. Schmidt and A. Penzkofer, Chem. Phys. 133 (1989) 297.

[30] Coumarin 314T. A New Improved Blue Green Laser Dye from Kodak, Kodak technical data sheet.

[31] R. Sens, Dissertation. Universität Siegen, FRG (1984).

[32] O.G. Peterson, J.P. Webb, W.C. McColgin and J.H. Eberly, J. Appl. Phys. 42 (1971) 1917.

[33] E. Lippert, Z. Electrochem. 61 (1957) 963.

[34] E. Lippert, W. Lüder, F. Moll, W. Nägele, H. Boss, H. Prigge and I. Seibold-Blankenstein, Angew. Chem. 73 (1961) 695.

[35] Z.R. Grabowski, K. Rotkiewicz, A. Siemiarczuk, D.J. Cowley and W. Baumann, Nouv. J. Chim. 3 (1979) 443.

[36] W. Rettig. J. Mol. Struct. 84 (1982) 303.

[37] W. Rettig, Angew. Chem. 98 (1986) 969; Angew. Chem. Intern. Ed. 25 (1986) 971.

[38] W. Rettig. Appl. Phys. B 45 (1988) 145.

[39] E.M. Kosower and D. Huppert, Ann. Rev. Phys. Chem. 37 (1986) 127.

[40] E. Lippert, W. Rettig, V. Bonačić-Koutecký, F. Heisel and J.A. Miehe, Advan. Chem. Phys. 68 (1987) I.

[41] S.J. Strickler and R.A. Berg, J. Chem. Phys. 37 (1962) 814.

[42] J.B. Birks and D.J. Dyson, Proc. Roy. Soc. A 275 (1963) 135.

[43] D.V. O'Connor and D. Phillips, Time-correlated Single Photon Counting (Academic Press, New York, 1984).

[44] W. Bäumler and A. Penzkofer, Chem. Phys. 140 (1990) 75.

[45] G.R. Fleming, Chemical Applications of Ultrafast Spectroscopy (Oxford Univ. Press, Oxford, 1986).

[46] J.M. Hicks, M.T. Vandersall, E.V. Sitzmann and K.B. Eisenthal, Chem. Phys. Letters 135 ( 1987$) 413$.

[47] R.C. Weast, ed., CRC Handbook of Chemistry and Physics, Ist. Student Edition (CRC Press, Boca Raton, 1988) p. F. 21. 
[48] J.B. Birks, Photophysics of Aromatic Molecules (WileyInterscience, New York, 1970).

[49] J.A. Barltrop and J.D. Coyle, Principles of Photochemistry (Wiley, New York, 1978).

[50] A. Penzkofer and Y. Lu, Chem. Phys. 103 (1986) 399.

[51] F. Dörr, Angew. Chem. 78 (1966) 457.

[52] E. Lippert, in: Optische Anregung Organischer Systeme, ed. W. Foerst (Verlag Chemie, Weinheim, 1966) pp. 342 ff.

[53] A. Dienes, C.V. Shank and A.M. Trozzolo, in: Creation and Detection of the Excited State, Vol. 2, ed. W.R. Ware (Dekker, New York, 1974) pp. 149 ff.

[54]E.M. Kosower, An Introduction to Physical Organic Chemistry, Part II (Wiley, New York, 1968).

[55] P.F. Barbara and W. Jarzeba, in: Advances in Photochemistry, Vol. 15, eds. D.H. Volman, G.S. Hammond and K. Gollnick (Wiley, New York, 1990) pp. 1 ff.

[56] P.F. Moulton, in: Laser Handbook, Vol. 5, eds. M. Bass and M.L. Stitch (North-Holland, Amsterdam, 1985) ch. 2.

[57] A. Seilmeier and W. Kaiser, in: Ultrashort Laser Pulses, Topics in Applied Physics, Vol. 60, ed. W. Kaiser (Springer, Berlin, 1988) p. 278.

[58] N.A. Borisevich, I.V. Kryukov, P.G. Kryukov, E.V. Khoroshilov, G.B. Tolstorozhev, M.Yu. Shakhbazian and A.V. Sharkov. Proceedings of the 6th International Symposium on Ultrafast Phenomena in Spectroscopy, Neubrandenburg, GDR, 23-27 August 1989 (Springer, Berlin ), to be published.

[59] H.E. Lessing and A. von Jena, in: Laser Handbook, Vol. 3, ed. M.L. Stitch (North-Holland, Amsterdam, 1979) ch. B6, pp. $753 \mathrm{ff}$.

[60] L.G.S. Brooker, A.C. Craig, D.W. Heseltine, P.W. Jenkins and L.L. Lincoln, J. Am. Chem. Soc. 87 (1965) 2443.

[61] C. Reichardt and E. Harbusch-Görnert. Liebigs Ann. Chem. 1983 (1983) 721.

[62] K. Dimroth, C. Reichardt, T. Siepmann and F. Bohlmann, Liebigs Ann. Chem. 661 (1963) 1.

[63] C. Reichardt, Liebigs Ann. Chem. 752 (1971) 64

[64] M. Magata and T. Kubota, Molecular Interaction and Electronic Spectra (Dekker, New York, 1970) ch. 8, pp. $371 \mathrm{ff}$.
[65] G. van der Zwan and J.T. Hynes, J. Phys. Chem. 89 (1985) 4181.

[66] W. Liptay, in: Excited States. Vol. 1, ed. E.C. Lim (Academic Press, New York, 1974) pp. 129ff.

[67] F. Rogowski, Fortsch. Chem. Forschung 4 (1963/65) 1.

[68] J. Stals, Rev. Pure Appl. Chem. 20 (1970) 1.

[69] M. Meyer and J.C. Mialocq, Opt. Commun. 64 (1987) 264.

[70] C. Rullière, Z.R. Grabowski and J. Dobkowski, Chem. Phys. Letters 137 (1987) 408.

[71] M. Meyer, J.C. Mialocq and B. Perly, J. Phys. Chem. 94 (1990) 98.

[72] H.J. Polland, T. Elsaesser, A. Seilmeier and W. Kaiser, Appl. Phys. B 32 (1983) 53.

[73] Zs. Bor, S. Szatmari and A. Müller. Appl. Phys. B 32 (1983) 101.

[74] P. Sperber, W. Spangler, B. Meier and A. Penzkofer, Opt. Quantum Electron. 20 (1988) 395.

[75] J. Hebling and J. Kuhl, Opt. Letters 14 (1989) 278.

[76] A. Penzkofer, Appl. Phys. B 46 (1988) 43.

[77] K.A. Hellwege and A.M. Hellwege, eds., Landolt-Börnstein, Vol. 2, 6th Ed. (Springer, Berlin, 1962) part 8.

[78] J.F. Coetzee, ed., Recommended Methods for Purification of Solvents and Tests for Impurities (Pergamon Press, Oxford, 1982).

[79] R. Arndt and R.E.D. McChung, J. Chem. Phys. 70 (1979) 5598.

[80] K.L. Oehme, F. Seifert, G. Rudakoff, W. Carius, W. Hölzer and O. Schröter, Chem. Phys. 92 (1985) 169.

[81] D.G. Patterson and J. Griffiths, J. Chem. Phys. 63 (1975) 2406.

[82] S.L. Whittenburg and C.H. Wang, J. Chem. Phys. 66 (1977) 4255.

[83] G.A. Kenney-Wallace, Phil. Trans. Roy. Soc. A 298 (1980) 309. 